Vol. 1, No. 2, 2020

Igor Murovanyi, Pavlo Mazyliuk

Lutsk National Technical University

75, Lvivska Str., Lutsk, 43000, Ukraine

(C) I. Murovanyi, P. Mazyliuk, 2020

https://doi.org/10.23939/tt2020.02.001

\title{
ANALYSIS OF SATURATION FLOW ON ISOLATED LANES OF CONTROLLED INTERSECTIONS WITH SIGNIFICANT TRAFFIC INTENSITY
}

\begin{abstract}
Summary. The methods and results of the investigation of intervals between vehicles during queue dissipation before controlled intersections with the further determination of saturation flow are reviewed in this paper. Having reviewed existing methods of determining the saturation in traffic flows, those are determined which provide the most certain results in conditions of intensive movement and take into account quite a large number of impact factors. Such methods are based on experimental measurement of intervals between vehicles during their passage through the stop-line in different directions of the controlled intersection. For the completeness of the analysis of such intervals, such factors are considered additionally as traffic composition and use of lanes by directions. Objects of the research are controlled intersections on approaches to which the slope is absent, there is no pedestrian and cyclist movement during the performance of turn, and conflicting traffic flows and also public transport stops in the zone of the intersection. The transitional research result is the determination of the number of vehicles that pass the stop-line during the permissive signal and time intervals between them, and the final result is the oncoming of saturation period on the lanes of straight and turns movement depending on traffic flow composition.
\end{abstract}

Key words: controlled intersection, the time interval between vehicles, saturation flow, traffic flow, traffic delay, traffic intensity, traffic flow composition, roadway, traffic light cycle, traffic light control, road users.

\section{INTRODUCTION}

In modern cities, to improve the organization of traffic flow movement, the latest automated systems of traffic control are implemented. Such decisions allow reacting rapidly to the fast growth of traffic intensity as the factor of an increase in the demand and mode of travel. Creation of multilevel automated systems of traffic control is based on the implementation of traffic light control systems which are controlled by traffic control center and can use such functions as permanent monitoring and gathering information about the state and directions of movement of road users flows (traffic flows, passenger and pedestrian flows), giving the priority to a certain group of road users, reorientation of the traffic flow by directions in different time of day, tracking accidents and emergencies on the road network (RN), compliance of movement schedules by public transport (PT), etc. The development of such elements of intelligent transport systems (ITS) is caused by the fast growth of demand on transportation with simultaneous reduction of time losses which is used for this and, at the same time, insufficient supply for the satisfaction of such needs. By the supply for the satisfaction of needs for transportation means the number and conditions of PT, restriction of free territories in cities for transport infrastructure implementation, imperfections of urban planning of cities territories which formed historically or under the influence of geographic and climate conditions. The simultaneous imposition of listed factors creates 
significant problems for road users, especially in peak periods, when traffic intensity during small time intervals (1-2 hours) in certain day periods significantly exceeds the average daily traffic intensity. Depending on the size and planning of the urban territory, such peak loads cause the increase in time losses on the travel and also economic costs for most residents. Based on the formulated, the aim of traffic organizers is operational management of road users flows with minimization of the impact of transport and urban planning factors on time losses during the travel by RN.

Special attention should be paid to the junctions of RN where road user flows change directions, redistribute or change the mode of travel. Such sections are intersections of city streets and roads. Exactly here, regardless of the way of movement control, the main delays in movement appear. The latest period of observation (up to 5 years) proves that in large cities where problems with traffic flows are the biggest, the absolute majority of intersections, especially on arterial streets of citywide and district importance, are transferred from uncontrolled to controlled. Such decisions are dictated, first of all, by the criteria of road safety, as the implementation of compulsory traffic light control is not always optimal from the point of traffic delay but allows separating traffic and pedestrian flows in time and space. Having information about practical intersections capacity we can claim that we have reliable information about the same value of this indicator for the whole street. Moreover, the capacity of the street determines the intersection with the least value of the given indicator which is located on the street.

The existence of reliable data about the state and conditions of road users flows on controlled intersections and construction on their basis the improved regularities (considering the larger amount of factors) will allow improving the quality of automated systems of traffic control functioning not only on specific intersections but on the whole city territory as many well-known models, formulated in previous decades whether not work at all or work with significant errors. Besides, such models should be adaptive and be based on operational information which can be received continuously with the help of technical means of traffic organization.

\section{RESEARCH STATEMENT}

Existing scientific approaches define that saturation flow is determined: experimentally by determining whether the maximal number of vehicles that pass the stop-line during the conditional "endless" duration of permissive signal or determination of time intervals between vehicles during the dissipation of the queue of conditional "endless" length; theoretically with the use of empirical dependencies which consider geometric parameters of the roadway, slope on the approach to the intersection, curvature of the trajectory of performance of further maneuver, and traffic flow distribution by the directions on the intersection. Based on the aforesaid, experimental research should be conducted in conditions of constant saturation on the lanes, i.e. within the significant intensity of vehicle arrival on the investigated approach by all methods. In practice, quite often the situation occurs when the use of different experimental methods for the same research objects gives results (values of saturation flow) which are significantly different from each other. And if compare the same results obtained with the use of experimental and theoretical methods then the situation is more interesting: in one case they coincide, in another, they can differ in 1.5-2 times.

Hypothetically, the dissimilarity of results can be justified by such judgments:

1. Movement conditions on approaches to the controlled intersection are not the same and such differences are caused by the regularities of traffic flow formation in different transport districts and their redistribution depending on the further direction of movement;

2. The time for conducting experimental research is chosen unsuccessfully, i.e. strict chronological boundaries of the peak load were not chosen properly which decreases the correlation between experimental and theoretical results;

3. The majority of well-known theoretical equalities were obtained in the period when traffic flow intensity and dynamic features of vehicles significantly differed from existing;

4. The factor of the driver is considered insufficiently which is defined by the complex of his personal, professional, and psychophysiological properties. 
Basing on well-known experimental methods and taking into account judgements given aforesaid, experimental measurements of saturation flow on isolated lanes of controlled intersections that serve only straight and turn traffic flows in the peak period are carried out, and their results are compared to theoretical. By isolated lane is this study means such a lane on the approach to a controlled intersection that serves traffic flow only in one direction.

\section{RELEVANCE OF THE STUDY}

As mentioned before, modern automated systems of traffic control allow quick and efficient operating traffic flows including redistribution signals on traffic light objects depending on the need (traffic intensity) by the directions on controlled intersections giving the priority to certain groups of road users (pedestrians, PT), etc. But, the usage of the adaptive systems of traffic light control is possible only on those intersections where traffic intensity is unsteadily distributed whether by directions or by periods. When traffic intensity is large on all approaches to the intersection, then traffic light systems are used with fixed control algorithms where the duration of traffic light signals is permanent and is determined by phase coefficients. Such coefficients are the correlation between the demand (ever-changing quantity - traffic intensity) and the supply (conditionally permanent quantity - saturation flow). From there, and also knowing the information about the regularities in traffic flow for some transport districts, an important task is the determination of the adequate value of saturation flow which could follow not ideal (theoretical) capacity but the real (practical). Insertion of such data into control algorithms of traffic light system will provide an opportunity to improve the effectiveness of traffic flow control not only on separate isolated controlled intersections but on their network which includes whole transport districts for which the same (or similar) regularities of road users' flows formation are common.

\section{THE AIM AND THE TASK OF THE STUDY}

The aim of this study is the determination of the experimental value of saturation flow on isolated lanes before controlled intersection based on the results of field research of intervals between vehicles and traffic composition.

In the service of research aim of, such tasks are formulated:

- determine the main factors which influence traffic flow formation in the zone of controlled intersection operation and conduct their differentiation by the level of impact within this research;

- carry out a theoretical analysis of methods and methodologies about the experimental and theoretical determination of saturation flow and also regularities, by which they are described;

- carry out field research to determine traffic flow composition, intervals between vehicles during queue dissipation on the permissive signal of a traffic light for controlled intersection which has isolated lanes;

- set the regularities of the change of time intervals between vehicles depending on traffic flow composition and further movement trajectory within a controlled intersection;

- determine and compare the obtained experimental value of saturation flow for isolated lanes for straight and turn movement directions with known theoretical values.

During the conducting of this research, such methods were used: field research for the determination of traffic intensity, traffic flow composition, and intervals between vehicles; theoretical research for the determination of the main factors and regularities in traffic flow on controlled intersection; system analysis during the determination of the main and the secondary factors of influence of traffic flow during its passage through the controlled intersection.

\section{ANALYSIS OF RECENT RESEARCH AND PUBLICATIONS}

The intensity of vehicle movement is related to the main primary indicators which are used for the design of a controlled intersection. At the same time, traffic intensity on controlled intersections divides into two categories [1]:

- the intensity of vehicle arrival to the intersection;

- the intensity of departure (dissipation) of the vehicle queue after turning on the permissive signal. 
The intensity of departure of vehicles is straightly connected to the value of saturation flow.

By the intensity of vehicle arrival to controlled intersection means equivalent hourly traffic intensity [1-3]. It is calculated as the relation of the number of vehicles to the time interval which is needed for these vehicles to pass a certain cross-street, for example, stop-line. As a rule, during the determination of equivalent hourly intensity, a time interval of less than one hour is considered. It should be noted that the intensity of vehicle arrival to the controlled intersection is evaluated in passenger car equivalent units per hour [1].

Certainly, traffic intensity changes during months, days, and hours, and also one hour. All these changes of intensity should be taken into account for the elements of $\mathrm{RN}$, in our case controlled intersections, operating efficiently in peak periods, i.e. without traffic jams on approaches to them [2].

Change of intensity during peak period is taken into account while analyzing the level of service of traffic flows on controlled intersections, herewith the assessment measures of traffic flow level of service are used which are based on 15-minute peak intervals [1, 2]. In Fig. 1, the example of the change in traffic intensity in 5-minute intervals is shown.

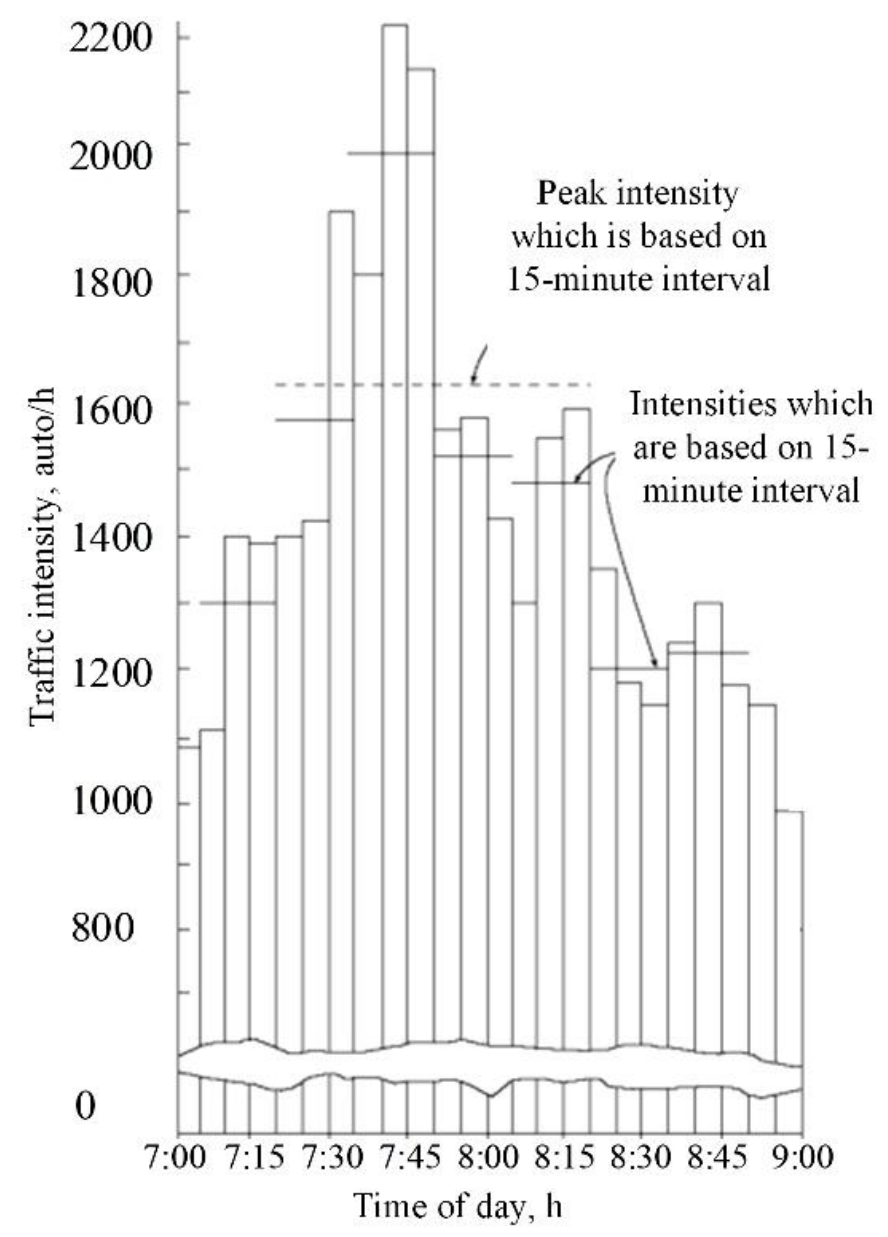

Fig. 1. Change of traffic intensity during peak period [1]

As result, the general traffic intensity which exceeds the capacity during peak hour will cause the oversaturation of the next hour.

Even though usually a 15 -minute interval is chosen as the investigation period, intervals of other duration can also be used. The intensity of vehicle arrival to the intersection can be obtained for the largest period, herewith the special specifying coefficient is used, which is called "peak hour factor" $[1,2]$.

The reduction of the traffic intensity to its peak value is carried out by several methods (Fig. 2). 


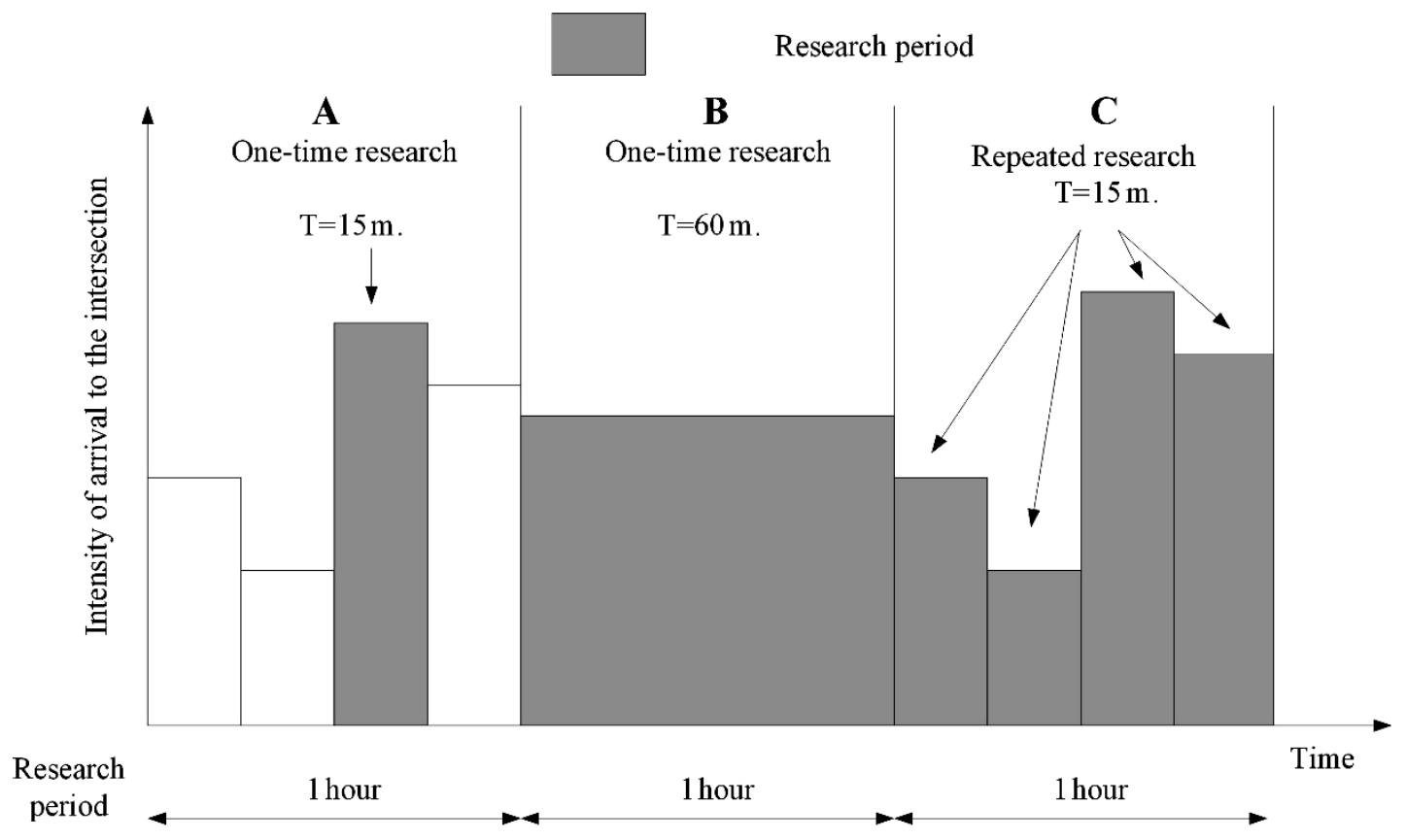

Fig. 2. Research of peak traffic intensity [1]

Method "A": duration of the investigated period is 15 minutes ( 0.25 hour). In this case, hourly peak intensity or p.c.u. peak intensity, obtained in a 15-minute interval, can be calculated by formula [1]:

$$
N_{p}=\frac{V}{P H F},
$$

where $N_{P}$ - p.c.u. peak intensity of vehicle arrival on the approach (lane) to the intersection, determined by 15-minute interval, p.c.u./h; $V$ - peak traffic intensity, determined during all peak hour, p.c.u./h; $P H F-$ peak hour factor (in the absence of data accepts $P H F=0.92$ ).

The main disadvantage of such a method is that only one 15-minute interval is considered but the queue on the investigated element of controlled intersection can stay after this interval as traffic intensity exceeds the capacity [1].

Method "B": research is carried out during the whole period $\mathrm{T}$ ( 1 hour). In this case, more critical periods can be taken into account, when the intensity of arrival exceeds the capacity of the investigated element of intersection what is not taken into account in method "A". The drawback of method " $B$ " is that as a result of the hourly period of investigation the intensity of vehicle arrival will be permanent during the whole hour. As a result of such an approach, the effect of the peak hour within the interval of investigation, when during a 15-minute interval the intensity exceeds

the average value of intensity per hour, will be lost. In this case, the risk of undervaluation of possible traffic delay during an hour on the investigated section of the intersection appears. As a result, if at the end of the investigated period there still is an end queue, it is necessary to continue the research on the same period until it will dissipate [1].

Method "C": research is carried out during the whole period T (1 hour), but it is divided into 15-minute intervals. In this case, there is an opportunity to consider the end queue which moves from one to another 15-minute research interval. As result, if the intensity of arrival exceeds its capacity, more precise values of delay can be obtained on the investigated element of controlled intersection [1].

Hourly traffic intensity is lead to maximal peak intensity which can be reached only during a 15-minute period. As result, the final value, which is used in calculations, will be surpassed, what will cause some increase in traffic delays assessment. During the design, it allows considering the maximal jump in intensity during peak hour. 
During many years of study of traffic flows on controlled intersections, several main parameters are outlined, one of which is saturation flow which is considered as capacity of the certain lane of approach to the controlled intersection [1].

Saturation flow is the main feature in the process of analysis and design of a controlled intersection.

Analyzing the studies of researchers from different countries, we can conclude that everyone formulated the definition of saturation flow in his way. For example, Yu. Kremenets [5] determines saturation flow as the maximal intensity of queue dissipation in a fully saturated phase. Such an assessment of saturation flow is traditional. A significant part of professionals considers saturation flow as permanent traffic intensity of passage the stop-line from the queue of big length [6-11].

At the same time, we can provide an example of a principally different understanding of the definition "saturation flow". In the controlled intersections design manual [1] saturation flow is lane capacity during continuous movement with the speed of $15 \mathrm{~km} / \mathrm{h}$. Yu. Vrubel [9] suggests that saturation flow is the average intensity of vehicle arrival from the stop-line during the permissive signal during the dissipation of quite a large queue. In his opinion, such a definition of saturation flow approaches to the definition of capacity during the permissive signal and considers also the lost time.

Statements of Webster about the permanent values of intervals in saturation flow allows simply approximating the number of vehicles that pass the stop-line $N(t)$ for time $t$, by linear equation [7]:

$$
N(t)=\frac{\left(t-L_{s}\right)}{q},
$$

where $q$ - the interval between vehicles in saturation flow, $\mathrm{s} ; L_{s}$ - starting time losses, $\mathrm{s}$.

In specialized literature, several types of different interpretations of saturation flow are given which are often significantly different from each other. For example, in the study [12] the saturation flow is defined as lane capacity during continuous movement with a speed of $15 \mathrm{~km} / \mathrm{h}$. In the paper [13] is said that saturation flow means traffic intensity in stop-line cross-section during dissipation from a given direction the queue of infinite length. In most cases, all formulations can be summarized by saying that saturation flow - let us call it $M$ - is the largest established intensity above the stop-line in the presence of long enough vehicle queues.

But, such formulation is not quite precise and in many cases causes notable differences. To show it, we should review the process of movement above the stop-line during the queue dissipation immediately after turning on the green signal. It is established that intervals of vehicles depart from the stop-line change approximately by the law, given in Fig. 3 [5]. The numerical value of intervals is equitable only for cars. For trucks and buses, they are bigger approximately $50 \%$.

Increased departure intervals of the first vehicles are related with driver' reaction, time losses on the gear actuation, and, mainly, the start of the movement and slow passage of stop-line because the small velocity in connection with the increase of safe distance between vehicles which was reduced to a minimum during their stop in the queue.

With the increase of a serial number of the vehicle in the queue, the speed under the stop-line increases and gradually stabilizes, intervals of departure also stabilize and depend mainly only on the dynamics and external dimensions of vehicles. It is proved that the stabilization of intervals undergoes at the level of 5-7 vehicles in queue [4].

It is known that in normal conditions established intervals of car departure $\left(T_{c}\right)$ are about $2 \mathrm{~s}$. Departure intervals of other vehicles $\left(T_{n}\right)$ are distributed similarly to $T_{c}$. If divide the range of intervals $T_{n}$ by $T_{c}$, then we get the coefficient of a given group of vehicles to cars, based on the theory of saturation flow (Fig. 4) [4]:

$$
K_{n}=\frac{T_{n}}{T_{c}} .
$$




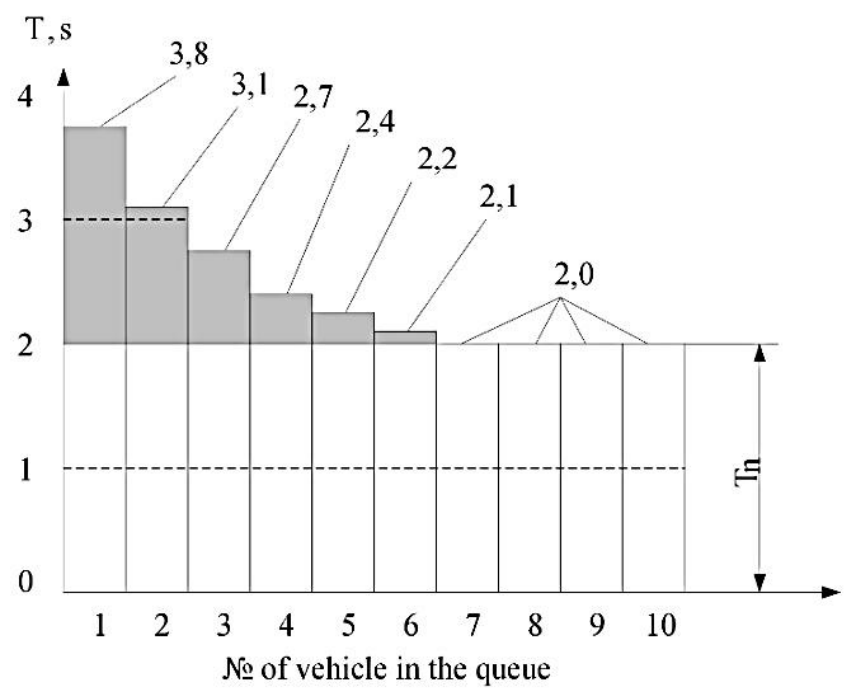

$a$

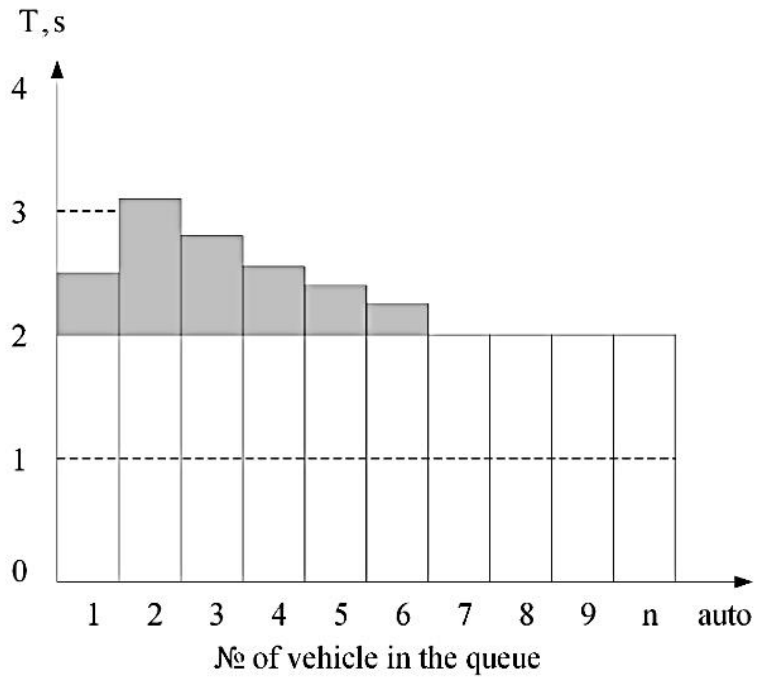

$b$

Fig. 3. Distribution of departure intervals from the stop-line after turning on the permissive signal [4]: $a$-according to Greenshields; $b$-according to measurement data of Vrubel; $T$-established departure interval, s; shaded zone - lost time

Fig. 4. Graphical interpretation of $K_{n}[4]$ : $T_{c}$-established intervals of car departure, $s$; $T_{n}$ - established intervals of departure of $i$ group of vehicles, $s$

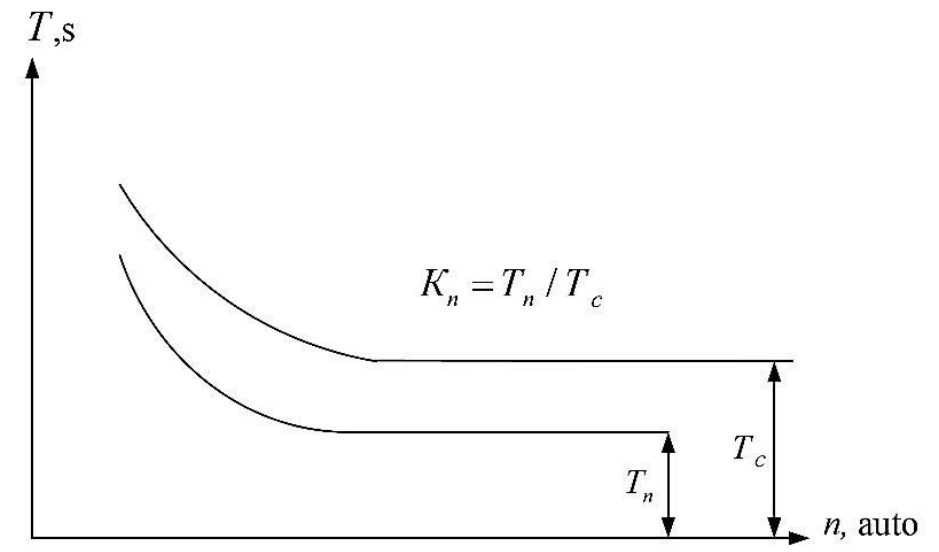

In case when the value of saturation flow cannot be measured on the location, the quantity of "ideal saturation flow" is used together with several adjusting coefficients which change it due to representative conditions of the location. For example, in the American 1985 Highway Capacity Manual, saturation flow, which is 1800 p.c.u./h, is reviewed as an "ideal saturation level" and is used with compliance with adjusting coefficients. Saturation flow $M$ in specified road conditions is determined from the equation [1]:

$$
M=M_{0} \cdot N \cdot f_{w} \cdot f_{H V} \cdot f_{G} \cdot f_{P} \cdot f_{B B} \cdot f_{A} \cdot f_{R T} \cdot f_{L T},
$$

where $M_{0}$ - ideal saturation flow, taken 1800 p.c.u./h; $N$ - number of lanes; $f_{w}$ - coefficient which considers lane width; $f_{H V}$ - coefficient which considers heavy vehicles; $f_{G}$ - coefficient which considers longitudinal slopes; $f_{P}$ - coefficient which considers street parking; $f_{B B}$ - coefficient which considers PT; $f_{A}$ - coefficient which considers area type; $f_{R T}$ - coefficient which considers right turns (also pedestrians); $f_{L T}-$ coefficient which considers left turns.

On the whole, the determination of saturation flow comes to the observation of vehicle queues which dissipate on the controlled intersection after turning on the permissive signal and consist only from cars. Besides, there should be conditions in which it's generally accepted the ideal saturation flow (lane width $3.5 \mathrm{~m}$, the slope on the approach to the intersection is $0 \%$, dry pavement, the absence of obstacles created by parked vehicles and PT stops, absence of conflicting pedestrian, cyclist and traffic flows, and also the absence of heavy vehicles (buses) in the flow) $[14,15]$. 


\section{PRESENTATION OF BASIC MATERIAL}

To carry out experimental research, controlled intersections in Lutsk city, where exist isolated lanes, were chosen.

The sequence of conducted experimental research was [1]:

1. Notation of the name of the intersection, the direction of an approach, lanes, time, weather conditions, special conditions (if necessary). Directions on the intersection and investigated lanes were graphically represented.

2. Before turning on the green signal (when in the previous phase the yellow signal was turned on) the researcher determined the number of vehicles that were in the queue and noted it in the form. This quantity was not used during the calculation of saturation flow directly but for certification of a sufficient number of vehicles in the queue for the provision of the stable saturation flow.

3. With the turning on of permissive signal, one of the researchers turned on the timer.

4. In the moment of passage of the front bumper of the first vehicle above the stop-line, the type of vehicle was recorded due to the used classification.

5. When the front bumper of the next vehicle (and so on in the queue) reached the stop-line, the vehicle was identified similarly to the first.

6. The researcher that worked with the timer (also recorded events) notated letters that were dictated by another researcher. Herewith, he held the timer within sight. Every five seconds the record was put into a new column of established form.

7. The researcher also watched for vehicles which joined the queue and recorded the end of saturation, when maximal long-continued traffic flow finished in every traffic light cycle. As a rule, for the straight direction, conflict-free left turn, or unlimited right turn, the saturation flow finished when during two joined intervals in $5 \mathrm{~s}$ less than 2 p.c.u. vehicles passed, ending on the last time intervals during which two or more vehicles were observed.

8. Determination of end of saturation in other cases was determined by the presence (absence) of expected vehicles. The researcher noted the vertical lane after the passage of the stop-line by the last vehicle to determine the finish of saturation flow in the cycle. Horizontal lane crossed those time intervals during which no vehicles were observed.

9. Measurements should include a minimum of 40 traffic light cycles with full saturation by duration of 20-30 s.

During the measurement, additional information can be used. For example, the calculation of vehicles which dissipate can be continued after finishing the saturation and also during the yellow signal and, if possible, during the red signal for the right-turn movement on the red signal. Although those data are not considered during the calculation of saturation flow, they contain information about the number of vehicles that could not dissipate during the green and yellow signals.

According to the formulated task and with the compliance of given methods, the measurement of the practical value of saturation flow on controlled intersections of city streets was carried out.

Although in the structure of traffic flow on all objects (controlled intersections) prevail cars, their share changes from $75 \%$ to $90 \%$. Such a change has an immediate impact on the process of queue dissipation during the permissive signal. Respectively, there is a change in experimental value of saturation flow. Time for carrying out the investigation was chosen such, when significant queues were observed on all approaches (theoretically accepted as the queue of infinite length), i.e. phases were wholly saturated. During the measurements, the number of every vehicle in the queue, its type and the time for which it passed the stop-line from the moment of turning on the permissive signal, and also interval with which they crossed the stop-line one by one was taken into account.

Answering the question of traffic flow composition as a significant factor that influences the quantities of saturation flow, the main attention in this scientific research is paid on the process of vehicle queue dissipation. On experimental sections, four traffic flow conditions, characteristic of them, are chosen by the criterion of traffic composition:

- traffic flow with only cars; 
- traffic flow with $10 \%$ of buses and $10 \%$ of heavy vehicles;

- traffic flow with $20 \%$ of buses and $20 \%$ of heavy vehicles;

- traffic flow with above $20 \%$ of buses and $20 \%$ of heavy vehicles.

By results of the data processing, the dependencies of the change of time intervals of turn queue dissipation (left turn) and for lanes that serve only straight flows are constructed (Fig. 5-8). These distributions are made for every lane in two variants: taking into account the first three vehicles in a traffic flow which started the movement on the permissive signal (Fig. 5, 7); without taking into account the first three vehicles time interval of which, due to the method, is with significant starting delay (Fig. 6,8).

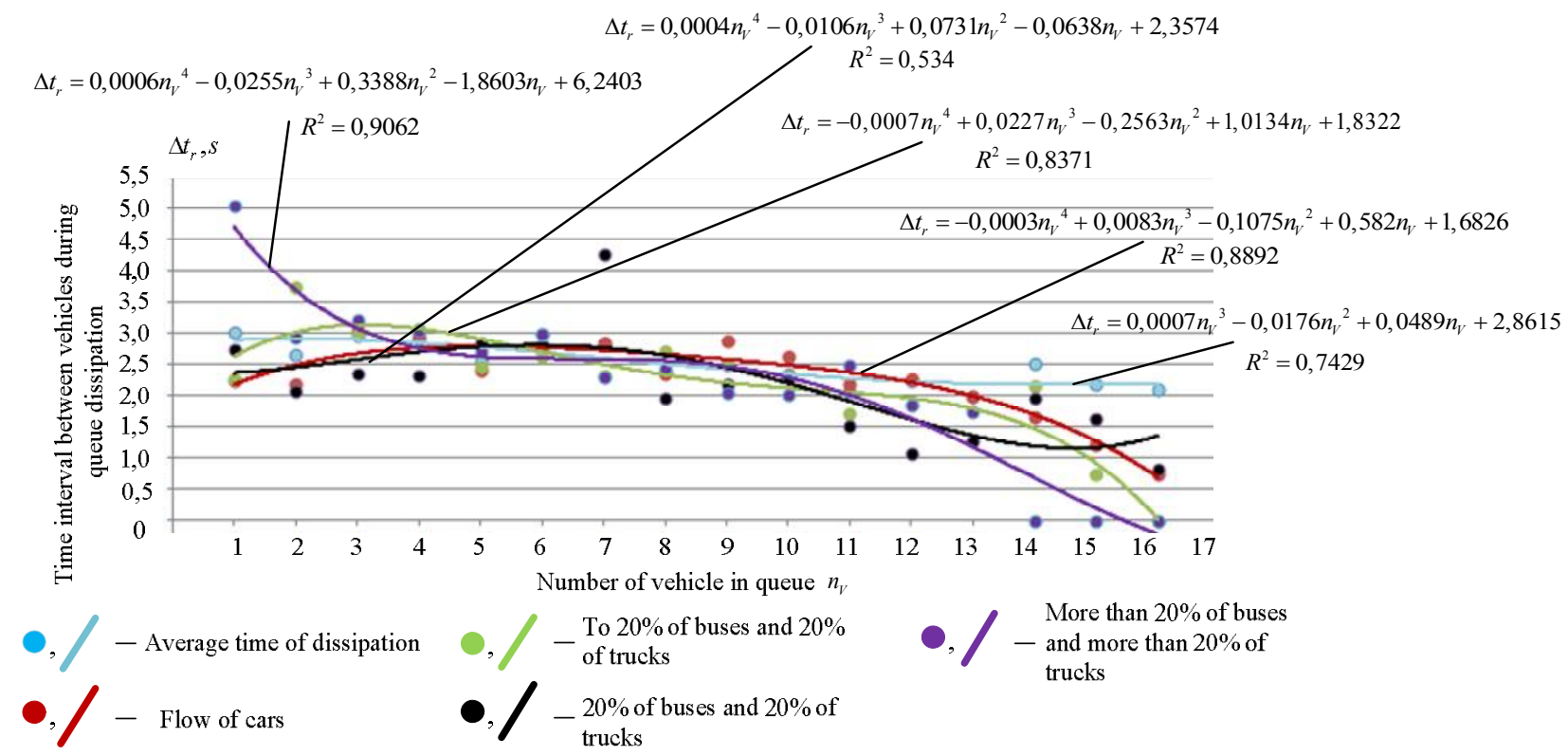

Fig. 5. Distribution of time intervals of queue dissipation during the performance of left-turn maneuver taking into account the first three vehicles

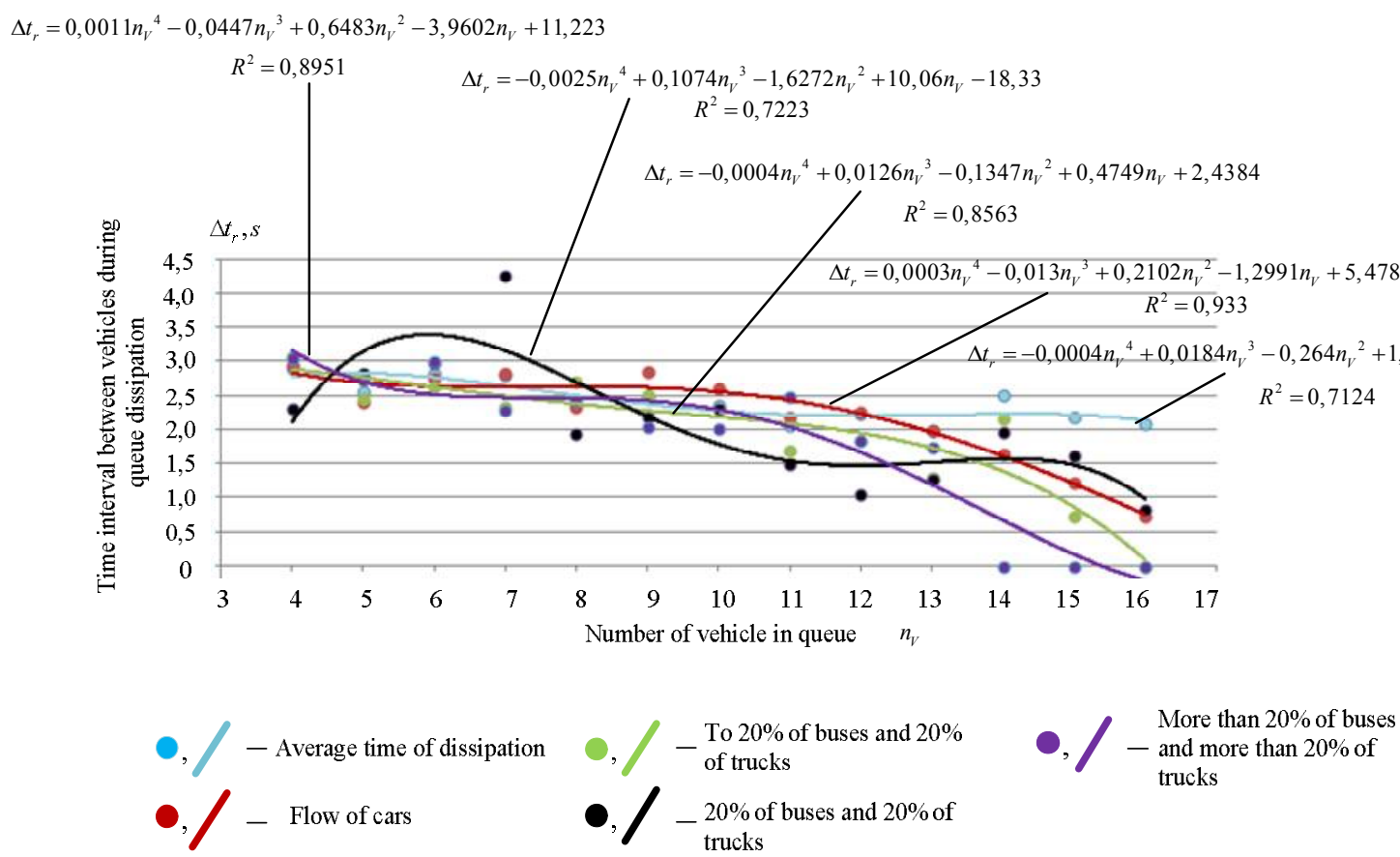

Fig. 6. Distribution of time intervals of queue dissipation during the performance of left-turn maneuver without taking into account the first three vehicles 


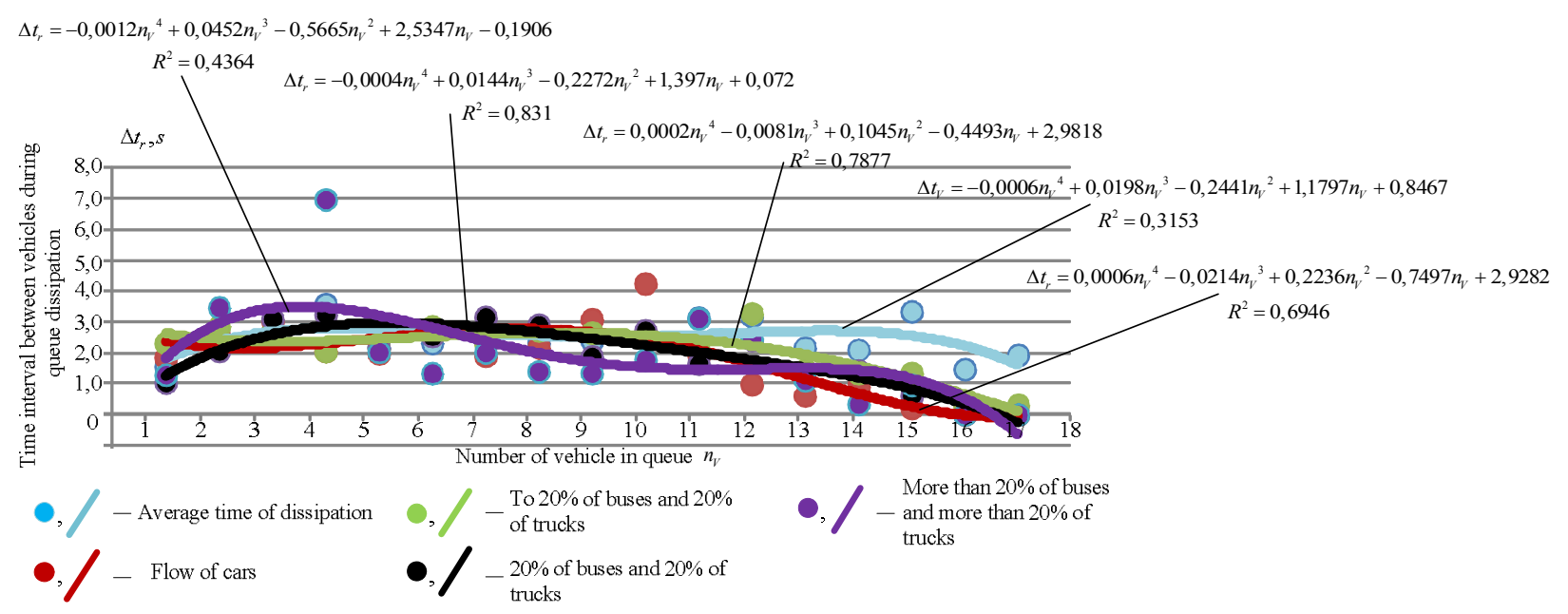

Fig. 7. Distribution of time intervals of queue dissipation of straight traffic flow taking into account the first three vehicles

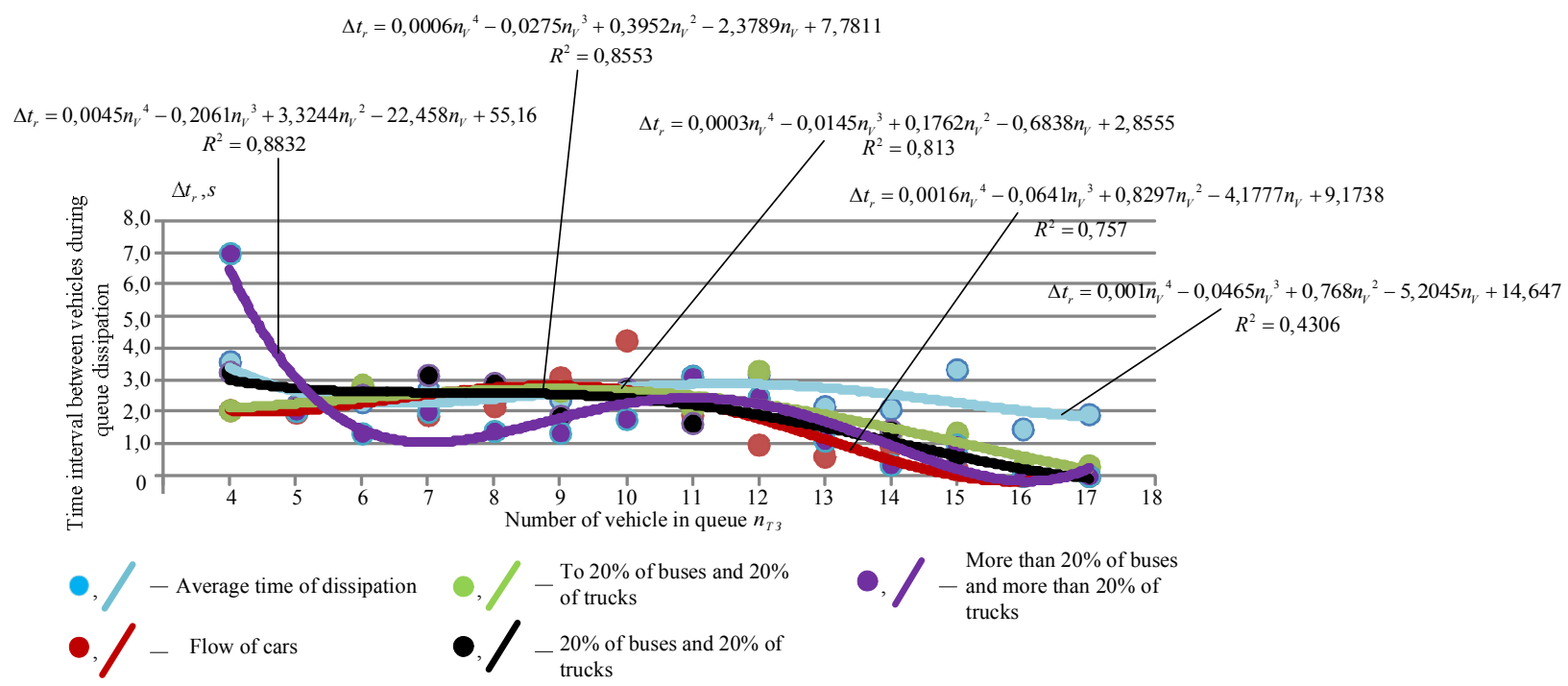

Fig. 8. Distribution of time intervals of queue dissipation of straight traffic flow without taking into account the first three vehicles

Having analyzed Fig. 5 and Fig. 7, we can see that for the first three vehicles intervals differ from the general tendencies which are common to the whole process of queue dissipation during the permissive signal. In particular, in figure 5, starting delay, which exceeds the time for which stop-line passed all next vehicles for almost 2 seconds, is common to all types of the queue. Here, the increase of intensity of dissipation with the further insignificant increase of interval on 5-7-th vehicles and further saturation of the flow is clearly expressed. We can also say that maximal capacity is clearly expressed during the passage of the eighth vehicle and all the next. A similar tendency is for straight vehicles (Fig. 7) with the only difference that polynomials that describe queues different by composition have less range of intervals, i.e. the impact of traffic flow composition is slightly smaller.

If not take into account the first three vehicles which, according to the method, have uncharacteristic intervals which influence the preciseness of the determination of saturation flow value, then the determination coefficient is more proportional for different by composition traffic flows, although the tendencies of the change of queue dissipation process remain. That is, the influence of the turn on the heavy vehicles is determinant, which is reflected by the larger dispersion of intervals in Fig. 6 in comparison with the tendencies reflected in Fig. 8. Also, it should be admitted, that on the x-axis the points which are located on the mark 0 that reflect time interval, show the end of the queue. 
Having analyzed research results, described above, the graphs of saturation growth in vehicle queue are constructed (Fig. 9-10).

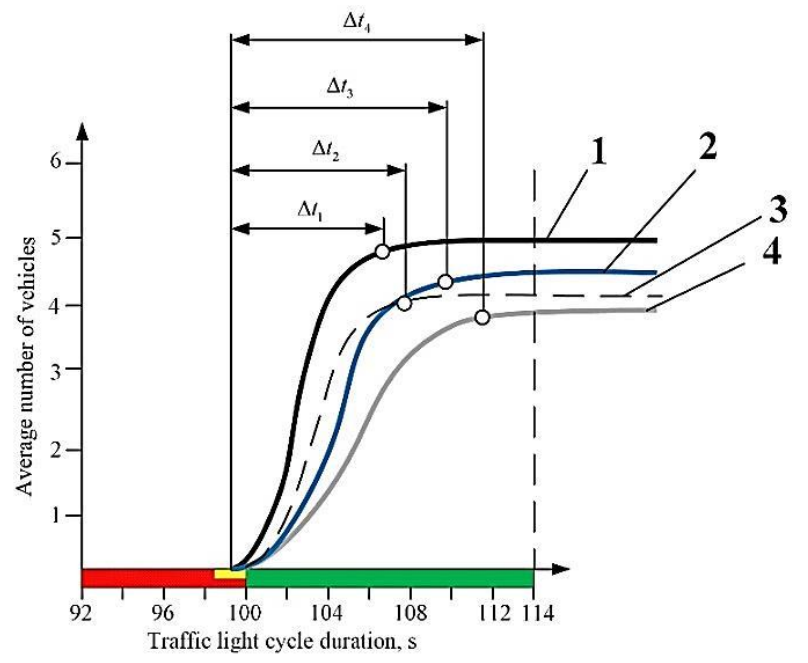

Fig. 9. Graph of saturation growth in vehicle queue which moves straight:

1 - traffic flow with only cars; 2 - traffic flow with $10 \%$ of heavy vehicles and buses; 3 - traffic flow with $20 \%$ of heavy vehicles and buses; 4 - traffic flow with above $20 \%$ of heavy vehicles and buses

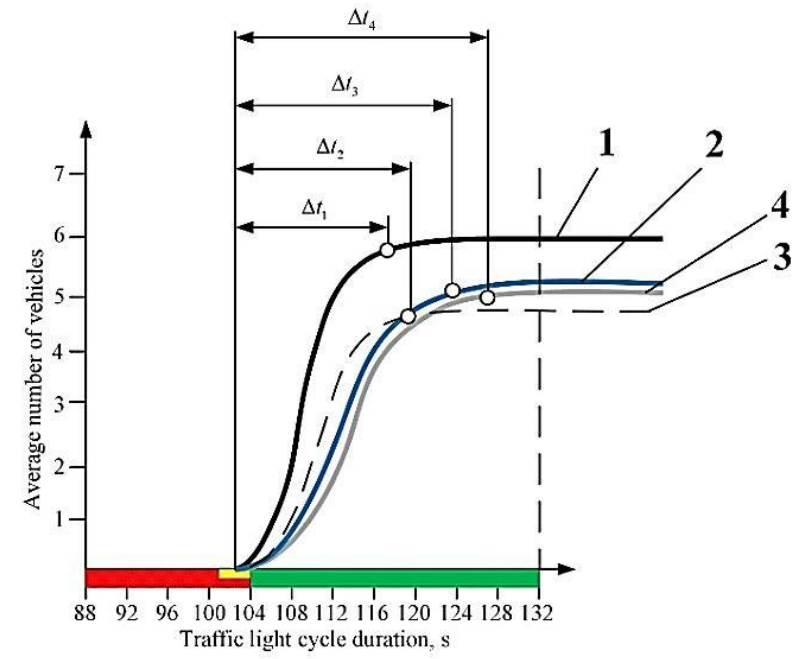

Fig. 10. Graph of saturation growth in vehicle queue which turns left:

1 - traffic flow with only cars; 2 - traffic flow with $10 \%$ of heavy vehicles and buses; 3 - traffic flow with $20 \%$ of heavy vehicles and buses; 4 - traffic flow with above $20 \%$ of heavy vehicles and buses

Graphs in Fig. 9 and 10 confirm again the difference in time between the start of saturation in the lane depending on the traffic flow composition and also the influence of the curvature radius of trajectory. This is because, during the turn, there is a change not only in the average number of vehicles which pass the stop-line in the same time interval from the moment of turning on the permissive signal but in the moment of the maximal capacity on the lane in conditions of traffic light control.

By the results of research of generally consolidated traffic flow, we can confirm that normative values of saturation flow, described in professional and normative literature, are achieved practically only with a large homogeneity of traffic flow (over $95 \%$ are cars). In all other cases, the experimental values differ from the theoretical by $200-400$ p.c.u./h what is quite a large operational margin, and this is without considering the slope of the roadway.

A similar situation was observed on the lanes which serve left turns. Here, the difference from theoretical measurements is up to 500 p.c.u./h.

Based on this, we can state that traffic flow composition together with roadway slope and a curvature radius of movement trajectory is one of the most important factors of the preciseness of saturation flow determination and, respectively, adequacy of calculated control parameters.

So, during the calculation of saturation flow, based on which the parameters of traffic light control are calculated, it is necessary to consider traffic flow composition through the appropriate coefficient, herewith it should have different values for straight and turn movement and be connected with the curvature radius of movement trajectory.

\section{CONCLUSIONS AND FUTURE RESEARCH PERSPECTIVES}

By the results of research, given in this article, we can make such general conclusions:

a) for every approach to the controlled intersection, it is necessary of carrying out separate measurements of experimental values of saturation flow which provides an opportunity to establish the impact of different factors which consider specific road conditions inherent only for a certain type of territory; 
b) maximal value of saturation flow is reached within high (95\% and more) level of homogeneity (cars) of traffic flow;

c) for isolated lanes, which serve straight traffic flows, the average value of time interval during queue dissipation is $1.5-2 \mathrm{~s}$ and it is reached after 6 or 7 vehicles from the queue, and for the same turn lanes $-2-2.5 \mathrm{~s}$;

d) increase in the share of freight and public transport by $20 \%$ increases the period of onset of saturation by $10-13 \mathrm{~s}$, i.e. decreases the effective duration of the phase.

So, the application of only theoretical values of saturation flow for different controlled intersections can cause significant operational margins and obtained, as a result of this, calculated time parameters of traffic light control reduce its effectiveness.

\section{References}

1. Levashev, A. H., Mikhailov, A. Yu. \& Holovnykh, I. M. (2007). Proektirovanie reguliruemykh peresechnii [Design of controlled intersections]. Irkutsk: IrHTU (in Russian).

2. Wolshon, B., \& Pande, A. (2016). Traffic engineering handbook. John Wiley \& Sons. (in English).

3. Fornalchyk, Ye. Yu., Hilevych, V. V. \& Mohyla, I. A. (2020). Modeliuvannia transportnykh potokiv [Traffic flow modeling]. Lviv: Vudavnytstvo Lvivskoi Politekhniky (in Ukrainian).

4. Gavrylov, E. V., Dmytrychenko, M. F., Dolia, V. K., Lanovyi, O. T., Lynnyk, I. E., \& Polishchuk, V. P. (2007). Organizatsiia dorozhnioho rukhu [Traffic organization]. Kyiv: Znannia Ukrainy (in Ukrainian).

5. Kremenets, Yu. A., Pecherskii, M. P. \& Afanasiev, M. B. (2005). Tekhnicheskie sredstva organizatsii dorozhnoho dvizhenia [Technical means for traffic organization]. Moskva: Izd-iy tsentr "Akademia" (in Russian).

6. Ji, Y., Tang, Y., Wang, W., \& Du, Y. (2018). Tram-Oriented Traffic Signal Timing Resynchronization. Journal of Advanced Transportation. Volume 2018. doi: 10.1155/2018/8796250 (in English).

7. Shi, J., Sun, Y., Schonfeld, P., \& Qi, J. (2017). Joint optimization of tram timetables and signal timing adjustments at intersections. Transportation Research Part C: Emerging Technologies. Volume 83. 104-119. doi: 10.1016/j.trc.2017.07.014 (in English).

8. Zhou, L., Wang, Yi., \& Liu, Ya. (2017). Active signal priority control method for bus rapid transit based on Vehicle Infrastructure Integration. International Journal of Transportation Science and Technology. Volume 6(2). 99-109. doi: 10.1016/j.ijtst.2017.06.001 (in English).

9. Vrubel, Yu.A. (2003). Poteri v dorozhnem dvizhenii [Losses in traffic]. Minsk: BNTU. (in Russian).

10. Fornalchyk, Ye. Yu., Mohyla, I. A., Trushevskyy, V. E., \& Hilevych, V. V. (2018). Upravlinnia dorozhnim rukhom na rehuliovanykh perekhrestiakh u mistakh [Traffic management on controlled intersections in cities]. Lviv: Vudavnytstvo Lvivskoi Politekhniky (in Ukrainian).

11. Vrubel, Yu. A. et al. (2011). Koordinirovannoe upravlenie dorozhnym dvizheniem [Coordinated control of traffic]. Minsk: BNTU (in Russian).

12. Vrubel, Yu. A (2007). Issledovania $\mathrm{v}$ dorozhnem dvizhenii: uchebno-metodicheskoe posobie $\mathrm{k}$ laboratornym rabotam [Research in traffic: study guide for laboratory work]. Minsk: BNTU (in Russian).

13. Scheffler, R., Strehler, M. (2017). Optimizing traffic signal settings for public transport priority. Proc. of the 17th Workshop on Algorithmic Approaches for Transportation Modelling, Optimization, and Systems (pp. 9:19:15) - Vienna, Austria. doi: 10.4230/OASIcs.ATMOS.2017 (in English).

14. Zhao, J., Li, P., Zheng, Z., \& Han, Y. (2018). Analysis of saturation flow rate at tandem intersections using field data. IET Intelligent Transport Systems, Volume 12(5), 394-403. doi: 10.1049/iet-its.2017.0092 (in English).

15. Nguyen, H. D. (2016). Saturation flow rate analysis at signalized intersections for mixed traffic conditions in motorcycle dependent cities. Transportation research procedia, Volume 15, 694-708. doi:10.1016/j.trpro.2016.06. 058 (in English).

Received 10.08.2020; Accepted in revised form 18.09.2020. 